\title{
DANCANDO COM A MORTE: ENFRENTAMENTO DA GRIPE ESPANHOLA NO CEARÁ (1918-1919)
}

LEIDIANE PRISCILLA DE PAIVA BATISTA UNIVERSIDADE FEDERAL DO CEARÁ FORTALEZA - CEARÁ - BRASIL

EDSON OLIVEIRA DE PAULA** ID UNIVERSIDADE FEDERAL DO CEARÁ FORTALEZA - CEARÁ - BRASIL

Conhecer a influência de uma pandemia em uma sociedade permite refletir sobre o sucesso ou fracasso das medidas adotadas no enfrentamento e projetar ações de combate em novos casos. Partindo dessa premissa, revisitou-se a gripe espanhola no Estado do Ceará a fim de analisar os impactos sociais causados e a reação das autoridades e da população. Para tanto, remontou-se o avanço da doença no Estado, os

\section{RESUMO} danos causados à sociedade e as medidas sanitaristas implementadas. A precariedade dos medicamentos, os altos preços e a incerteza sobre sua eficácia foram problemas enfrentados a época. Apesar de estabelecer ações para contenção e enfrentamento da doença, o Estado e alguns médicos realizaram campanha de desinformação, menosprezando os impactos da doença no intuito de acalmar a população e minimizar impactos à economia.

Palavras-chave: Pandemia; Influenza; Bailarina; Negacionismo.

\section{ABSTRACT}

Knowing the influence of a pandemic in a society allows us to reflect on the success or failure of the measures adopted in coping and to project combat actions in new cases. Based on this premise, the Spanish flu was revisited in the State of Ceará in order to analyze the social impacts caused and the reaction of the authorities and the population. To this end, the advance of the disease in the State, the damage caused to society and the sanitary measures implemented were reassembled. The precariousness of medicines, high prices and uncertainty about their effectiveness were problems faced at the time. Despite establishing actions to contain and cope with the disease, the State and some physicians conducted a disinformation campaign, disregarding the impacts of the disease in order to calm the population and minimize impacts on the economy.

Keywords: Pandemic; Influenza; Ballerina; Denialism.

\footnotetext{
* Mestre em Desenvolvimento e Meio Ambiente (UFC) e Doutoranda em Ciências Marinhas Tropicais pela Universidade Federal do Ceará. E-mail: leidianepriscilla@gmail.com.

** Mestre em Desenvolvimento e Meio Ambiente (UFC) e Doutorando em Geografia pela Universidade Federal do Ceará. E-mail: edsonoliveirapx@gmail.com.
} 


\section{INTRODUCÃO}

Pandemia ocorre quando uma doença afeta amplos grupos populacionais, atingindo vários países e mais de um continente. As pandemias assolam a humanidade desde os tempos mais remotos. A Peste de Atenas, em 430 a.C., é uma das mais antigas que se tem registro ${ }^{1}$. Observa-se, ao longo da história, uma periodização de eventos epidemiológicos que acometem a sociedade, gerando intensas consequências demográficas e econômicas. Com isso, as sociedades humanas precisam buscar meios para conviver com as consequências das doenças contagiosas que surgem e ressurgem esporadicamente.

Ao longo dos anos, o Brasil enfrenta o ressurgimento de doenças infecciosas tidas como erradicadas e a manifestação de enfermidades até o momento desconhecidas. Ao longo da história estas crises foram intensificadas pela ausência de liderança dos governantes, culminaram e culminam com a banalização do número de vítimas e com o agravamento de enfermidades evitáveis ${ }^{2}$. Dessa forma, nota-se que as epidemias passam por um ciclo que começa pela negação, segue pela ressignificação e resignação, findando no olvidamento ${ }^{3}$.

Conhecer a influência de pandemias na história de um local, permite compreender os principais impactos gerados no sistema de saúde, na demografia e no sistema financeiro, assim como, as políticas e práticas sanitaristas adotadas para enfrentá-las. Deste modo, é possível refletir sobre o sucesso ou fracasso das medidas adotadas no enfrentamento de pandemias passadas e projetar ações de combate em novos casos.

Diante do exposto, no presente estudo buscou-se compreender o histórico da gripe espanhola no Ceará (1918-1919). Neste intuito, analisou-se os principais impactos sociais causados por essa pandemia, assim como as medidas de saúde pública adotadas para enfrentála. Para isso, realizou-se revisão bibliográfica do tipo narrativa, na qual a história da gripe espanhola no Ceará foi descrita e discutida de maneira teórica e contextual, abordando o recorte temporal entre agosto de 1918 e maio de 1919. A pesquisa foi feita no acervo do Instituto do Ceará - Histórico, Geográfico e Antropológico, em documentos e relatórios oficiais, e periódicos digitalizados disponíveis na Hemeroteca Digital da Biblioteca Nacional.

\footnotetext{
${ }^{1}$ TUCIDIDES. A história da guerra do Poliponeso. Brasília: Editora UnB; 2001, p. 47-54.

2 CUETO, M. El regreso de las epidemias: salud y sociedad en el Perú del siglo XX. Lima: Instituto de Estudios Peruanos, 2020.

${ }^{3}$ ROSENBERG, C. E. Explaining epidemics and Other Studies in the History of Medicine. Cambridge: Cambridge University Press, 1992.
} 


\section{VINDA DE ALÉM-MAR. A CHEGADA DA "ESPANHOLA" AO CEARÁ}

Em abril de 1918, enquanto vivenciava a primeira guerra mundial, a humanidade foi atingida pela pandemia da gripe espanhola. Muito embora não haja consenso no meio científico sobre o país no qual ela se originou ${ }^{4}$, a gripe recebeu esse nome por ter sido a Espanha o primeiro local a reportar a doença.

Causada por um vírus de influenza do subtipo H1N1, a patologia demonstrou-se altamente contagiosa e de fácil disseminação. Numa época em que as populações tinham contato limitado entre si, a propagação do surto foi acelerada pelo contexto militar da Primeira Guerra Mundial ${ }^{5}$. O agente infeccioso causador era ainda desconhecido, motivo pelo qual as informações sobre prevenção e manejo da doença foram precárias ${ }^{6}$.

Os principais sintomas manifestados eram: febre, espirros, secreção nasal, dor de cabeça, dor de garganta e, nos casos mais graves, pneumonia, cianose ${ }^{7}$ e hemorragia ${ }^{8}$. A sensação das vítimas era de morte por afogamento. A faixa etária mais afetada foi entre 18 e 40 anos, acreditando que metade da população mundial na época tenha contraído a doença ${ }^{9}$. As mortes são estimadas entre 50 e 100 milhões de pessoas ${ }^{10}$, sendo considerado o maior desastre demográfico do século XX.

Como medida para controlar a propagação da virose, no mundo foram predominantes as orientações de distanciamento social e interrupção de diversas atividades, como: suspensão de aulas escolares e paralisação do comércio em vários setores, de modo que muitas foram à

\footnotetext{
${ }^{4}$ TRILlA, A.; TRILLA, G.; DAER, C. The 1918 "Spanish flu” in Spain. Clinical infectious diseases, v. 47, n. 5, p. 668-673, 2008 , p. 668.

${ }^{5}$ RADUSIN, M. The Spanish flu, part II: The second and third wave. Vojnosanitetski pregled, v. 69, n. 10, p. 917-927, 2012, p. 919.

${ }^{6}$ SILVEIRA, A. J. T. A medicina e a influenza espanhola de 1918. Tempo, v. 10, n. 19, p. 91-105, 2005, p. 96.

${ }^{7}$ Sintoma de coloração azul arroxeada na pele, unhas, lábios e/ou em torno dos olhos.

${ }^{8}$ STEVENS, K. M. The pathophysiology of influenzal pneumonia in 1918. Perspectives in biology and medicine, v. 25, n. 1, p. 115-125, 1981, p.117.

${ }_{9}^{9}$ POTTER, C. W. A history of influenza. Journal of applied microbiology, v. 91, n. 4, p. 572-579, 2001, 576.

${ }^{10}$ A quantidade exata nunca poderá ser definida. Em revisão aos dados de mortalidade sobre a pandemia de gripe espanhola publicados em todo o mundo, Johnson; Mueller (2002) chegaram à estimativa de 50 milhões. Contudo, considerando-se as subnotificações, as regiões do mundo que não possuem dados e a carência de informações sobre a mortalidade entres populações indígenas, os autores assumem que este número possa chegar a 100 milhões. Consultar: JOHNSON, N. P.; MUELLER, J. Updating the accounts: global mortality of the 1918-1920 "Spanish" influenza pandemic. Bulletin of the History of Medicine, v. 76, n. 1, p. 105-115, 2002, p. 115.
} 
falência ${ }^{11}$. Prevaleceu a automedicação com drogas farmacêuticas e remédios caseiros, incluindo o consumo de álcool como forma de prevenção à gripe ${ }^{12}$.

Em 13 de agosto de 1918, o Brasil enviou uma Missão Médica Especial para atuar em um hospital temporário na França durante a guerra. Antes de chegar ao seu destino, o navio passou em Dakar, capital de Senegal (África Ocidental), onde os tripulantes provavelmente contraíram a influenza espanhola ${ }^{13}$. Muitos foram acometidos pela doença, havendo óbito de vários missionários e marinheiros. Entres eles, os médicos cearenses Paulo de Mello Andrade (tenente) e Pedro Monteiro Gondim (capitão) ${ }^{14}$ faleceram vítimas da gripe no mês de setembro de $1918^{15}$. Receber a notícia da tragédia sofrida pela missão militar brasileira e do padecimento de seus conterrâneos trouxe proximidade aos cearenses com a pandemia, que até então apresentava-se como problema distante que afetava somente o restante do mundo.

A “bailarina" - nome também dado à doença em referência à Espanha - chegou em solo brasileiro pelo navio britânico Demerara, que desembarcou passageiros nos portos de Recife, Salvador e Rio de Janeiro, em setembro de $1918^{16}$. A notícia da chegada da gripe tomou conta rapidamente dos noticiários e o pânico se espalhou entre a população. Sem demora, a pandemia chegou à Paraíba, ao Espírito Santo e continuou a se disseminar ao longo do território nacional. De tal modo que, em outubro do mesmo ano, esteve presente em todas as principais cidades brasileiras e alcançou até mesmo regiões mais isoladas, como pequenas cidades interioranas e territórios indígenas ${ }^{17}$.

Como medidas de saúde pública, recomendou-se evitar aglomerações e criou-se postos médicos e hospitais provisórios ${ }^{18}$. Apesar das medidas, faltaram leitos hospitalares para os doentes e caixões para enterrar os mortos. No Rio de Janeiro, a grotesca exibição pública de cadáveres caídos nas ruas, em avançado estado de putrefação ${ }^{19}$, ou expostos nas janelas das

\footnotetext{
${ }^{11}$ KHODR, O. B. O Pesadelo Econômico Moderno: a pandemia e a possível depressão da nova década. Boletim Economia Empírica, v. 1, n. 2, p. 3-7, 2020, p. 5.

12 SAUNDERS-HASTINGS, P. R.; KREWSKI, D. Reviewing the history of pandemic influenza: understanding patterns of emergence and transmission. Pathogens, v. 5, n. 66, p. 1-19, 2016, p. 5.

${ }^{13}$ SILVA, C. E. M. A missão médica especial brasileira de caráter militar na Primeira guerra mundial. Revista Navigator, v. 10, n.20, p. 94108, 2011, p. 100 .

${ }^{14}$ HEMEROTECA DIGITAL DA BIBLIOTECA NACIONAL. A Lucta. A missão médica. Sobral, 01 out. 1918, ano V, n. 230.

15 STUDART, G. Ephemerides Cearenses. Revista Trimensal do Instituto do Ceará. Ano 32, p.252-258, 1918, p. 257.

${ }^{16}$ BERTUCCI, L. M. Gripe A, uma nova "espanhola"? Revista da Associação Médica Brasileira, São Paulo, v. 55, n. 3, p. 230-231, 2009a, p. 230.

${ }^{17}$ SCHWARCZ, L. M.; STARLING, H. M. A Bailarina da Morte: a gripe espanhola no Brasil. São Paulo: Companhia das Letras, 2020 , p. 34.

${ }^{18}$ BERTUCCI, 2009a, p.230.

${ }^{19}$ HEMEROTECA DIGITAL DA BIBLIOTECA NACIONAL. A Lucta. Carnaval versus Grippe. Sobral, 23 abr. 1919 , ano V, n. 261.
} 
casas ficou na memória popular. Foi recorrente a abertura de valas comuns, onde se despejavam dezenas de corpos de acometidos pela doença ${ }^{20}$.

Embora cogite-se que morreram 30 mil pessoas no Brasil vítimas da gripe espanhola, esse é um dado não oficial. Essa informação é difícil de ser obtida, pois, certamente, muitas pessoas acometidas pela doença sequer conseguiram atendimento médico-hospitalar. Além disso, na época não havia um banco de dados nacional unificado e muitas cidades não reportaram os casos, incorrendo em forte subnotificação. Mais do que isso, não existia órgão equivalente a um ministério da saúde ou um sistema público de saúde unificado capaz de desenvolver planos, políticas de saúde pública ou estratégias capazes de debelar o flagelo, cabendo a cada Estado designar suas próprias estratégias no enfrentamento da doença ${ }^{21}$. Há ainda de considerar a carência de dados sobre o número de acometido e mortos entre as populações indígenas.

Em Fortaleza, as notícias do avanço da doença no país, deixou em alerta as autoridades sanitárias. Em novembro de 1918, o Governo do Ceará oficializou a já existente Diretoria Geral de Higiene com o decreto $n^{\circ}$ 1643. Entre as suas incumbências estava a fiscalização da medicina, a divisão das responsabilidades dos serviços de saúde entre Estado e municípios, a orientação para o isolamento dos doentes e a fiscalização das condições sanitárias de habitações e outros edifícios da cidade ${ }^{22}$.

Em uma época em que a microbiologia e suas descobertas estavam em alta na Europa, o Regulamento da Diretoria Geral de Higiene do Ceará buscou aplicar os tratados europeus de higiene pública ao compilar ideias higienistas, inspirando-se nas normas adotadas pela legislação francesa de $1902^{23}$. O regulamento cearense previa: medidas de vigilância, como a inspeção de vias e espaços públicos; a averiguação a propriedades particulares, suas condições de higiene; bem como o quadro de saúde dos moradores; a preconização da segregação de doentes, a higienização de seus pertences e do ambiente em que se instalavam, $\operatorname{etc}^{24}$.

\footnotetext{
${ }^{20}$ SANTOS, R. A. O Carnaval, a peste e a 'espanhola'. História, Ciências, Saúde-Manguinhos, v. 13, n. 1, p. 129-158, 2006, p. 137.

${ }^{21}$ SCHWARCZ; STARLING, 2020, p. 172.

22 CEARÁ. Decreto Legislativo N. ${ }^{\circ} 1643$, de 8 de novembro de 1918. Regulamento da Directoria Geral de Hygiene. Fortaleza: Est. Graphico A. C. Mendes, 1919.

${ }^{23}$ COSTA, M. C. L. Capítulos de geografia histórica de Fortaleza. Fortaleza: Imprensa Universitária, 2017 , p. 46.

${ }^{24}$ CEARÁ, 1919.
} 
O Diretor de Higiene a época (Dr. Carlos da Costa Ribeiro) e o Inspetor de Saúde dos portos (Dr. Manuelito Moreira) passaram a estudar a enfermidade e buscar meios de evitar que ela chegasse ao Ceará ${ }^{25}$. Ao se comunicarem com o Diretor de Saúde Pública Nacional, Dr. Carlos Seidl, receberam a resposta de que: “[...] a pandemia era inevitável, e o melhor que tínhamos a fazer seria recebê-la de braços abertos em vez de mostrar-lhe os punhos cerrados e impotentes" ${ }^{26}$. Pelo desconhecimento da natureza da moléstia e de como combatê-la, além da incapacidade do sistema de saúde público nacional em enfrentar a crise, Seidl foi bastante criticado pelos jornais e gazetas do país, passando a "espanhola" a ser conhecida como o "mal de Seidl",27.

Em relatório da Diretoria Geral de Saúde, Carlos Ribeiro indicou as providências tomadas para a vigilância e a quarentena do porto de Fortaleza:

[...] isolávamos a ponte de desembarque por meio de uma força embalada e proibimos o ingresso de quem quer que fosse, além das autoridades sanitárias, políticas ou aduaneiras necessárias ao serviço. Instalava-se aí um desinfetório para todas as roupas e bagagens de passageiros desembarcados e malas postas, tomávamos minuciosas notas dos destinos destes, a fim de exercermos a vigilância médica. E tínhamos de prontidão uma turma para conduzir para o isolamento, que improvisávamos na véspera, qualquer doente desembarcado ${ }^{28}$.

Apesar dos esforços, a gripe espanhola chegou em Fortaleza entre o final de setembro ${ }^{29}$ e os primeiros dias de outubro de $1918^{30}$ no navio brasileiro Vapor Ceará, que veio do sul do país e trouxe a bordo pessoas acometidas pela patologia. Pelo que remeteram os jornais da época, esse não foi o único navio com enfermos a chegar. Havia denúncias de embarcações que aportaram em Camocim sem haver fiscalização e nem isolamento dos doentes da espanhola ${ }^{31}$.

\footnotetext{
${ }^{25}$ SILVA, J. T. S. Mensagem apresentada pelo presidente do estado à Assembleia Legislativa do Ceará. Fortaleza, 01 jul.1919, p. 30. ${ }^{26}$ RIBEIRO, C. C. Relato da Diretoria Geral de Saúde: 31 de maio de 1919. Fortaleza: Tipografia Moderna, 1919 , p. 6.

${ }^{27}$ GOULART, A. C. Revisitando a espanhola: a gripe pandêmica de 1918 no Rio de Janeiro. História, ciências, saúde-Manguinhos, v. 12, n. 1, p. 101-142, 2005, p. 134.

${ }^{28}$ RIBEIRO, 1919, p. 6 e 7.

${ }^{29}$ SILVA, 1919, p. 30.

${ }^{30}$ RIBEIRO, 1919, p. 6

${ }^{31}$ HEMEROTECA DIGITAL DA BIBLIOTECA NACIONAL. Folha do Littoral. O nosso saneamento. Camocim, 25 mai. 1919, ano 2, n. 49.
} 
Em 12 de outubro, o navio Pará vindo de Recife aportou em Natal (Rio Grande do Norte) com passageiros e parte da tripulação acometidos de influenza espanhola ${ }^{32}$. O jornal Diário de Pernambuco informou que no dia 14 daquele mês faleceu a bordo "o Sr. Mozart Barrozo, comerciante em Fortaleza e que viajava com destino a essa cidade", 33 vítima da influenza espanhola. Apesar de estar com vários passageiros doentes, entre eles o médico de bordo, a embarcação zarpou no dia 15 do mesmo mês, seguindo seu trajeto e cumprindo suas escalas.

\section{“NÃO HÁ O QUE TEMER": AS ACÕES DAS AUTORIDADES SANITÁRIAS ANTE A PANDEMIA}

Ao comunicar que a pandemia havia se instalado em Fortaleza, a Diretoria Geral de Higiene buscou acalmar a população dizendo não haver motivo para pânico, pois tratava-se de uma patologia benigna, com baixo número de óbitos, do qual "a metade morre de medo; os outros porque a moléstia se tenha localizado em um órgão (pulmão, garganta, etc.) já doente ou fraco" 34 .

O negacionismo das evidências científicas perante uma pandemia, como ocorre atualmente no contexto da Covid-19, é recorrente na história humana ${ }^{35}$. Por muitas vezes, negar a ciência e os fatos históricos é uma opção política com o propósito de proteger a economia. Fazer a população acreditar não haver risco de contágio e/ou de morte é um subterfúgio para garantir que não se deixe de trabalhar ou adquirir bens de consumo para manter uma rotina de normalidade ante uma situação pandêmica, na qual muitos de seus semelhantes morrem massivamente sem ter acesso a atendimento médico-hospitalar e sem sequer ter sido descoberto um tratamento comprovadamente eficaz. Este tipo de estratégia visa enfraquecer o discurso científico, dificultando ainda mais o combate ao vírus.

\footnotetext{
${ }^{32}$ HEMEROTECA DIGITAL DA BIBLIOTECA NACIONAL. Diario de Pernambuco. A Influenza Espanhola. Recife, 15 out. 1918, ano 94, n. 284.

${ }^{33}$ HEMEROTECA DIGITAL DA BIBLIOTECA NACIONAL. Diário de Pernambuco. A Influenza Espanhola. Recife, 17 out. 1918, ano 94, n. 286.

${ }^{34}$ HEMEROTECA DigitAl DA BIBLIOTECA NACIONAL. A Lucta. Communicado da Directoria Geral de Hygiene. Sobral, 23 out. 1918, ano V, n. 233.

${ }^{35}$ ALMEIDA, M. A. P. A epidemia de cólera de 1853-1856 na imprensa portuguesa. História, Ciências, Saúde - Manguinhos, Rio de Janeiro, v.18, n.4, p.1057-1071, 2011, p. 1064.; SOUZA, C. M. C. A gripe espanhola em Salvador, 1918: cidade de becos e cortiços. História, ciências, saúde-Manguinhos, v. 12, n. 1, p. 71-99, 2005, p. 82 e 83.
} 
No contexto da gripe espanhola, esse discurso negacionista em prol dos interesses capitalistas acelerou a disseminação da doença e aumentou sua letalidade, principalmente entre a população mais pobre, desprovida de acesso a serviços de saúde. Potencializando essa situação, somava-se a alta nos preços de medicamentos e de alimentos em virtude da Primeira Guerra. O Brasil ainda não contava com um sistema público de saúde, uma vez que, o SUS (Sistema Único de Saúde) só seria criado em 1988, seguindo as determinações da Constituição promulgada naquele ano.

Endossando as ideias negacionistas, o médico cearense Theodorico Costa publicou matéria afirmando a benignidade da gripe e, ao relatar o desespero instalado entre os fortalezenses, disse não haver motivo racional para tamanho pavor, pois:

[...] está provado pelas estatísticas que o fantasma espanhol é de forma benigna, e tão benigna que em 117 mil atacados no Recife apenas cento e quatro vieram a falecer num dia, o que quer dizer um óbito para mil pessoas. [...] Não há razão para esse medo. Cada um ponha em pratica a sua higiene individual e estamos certos de que esse vento saturado da toxina vagabunda há de passar sem fazer estragos. [...] Tudo mais é aflição sem razão de ser; é temer diante de um mal que nada tem de assustador e de mortífero ${ }^{36}$.

Após surgirem alguns casos isolados, como o de um rapaz na rua Sampaio $^{37}$ e alguns soldados do exército, logo surgiram em vários pontos da cidade centenas de doentes ${ }^{38}$. Deste modo, a Diretoria Geral de Higiene buscou medidas para evitar aglomerações. As aulas escolares e procissões religiosas foram suspensas. Embora não se tenha conseguido fechar os cinemas, a frequência de público era insignificante ${ }^{39}$. No Dia de Finados de 1918, o Diretor Geral de Higiene estabeleceu que o cemitério São João Batista funcionasse apenas para enterros, sendo suspensas as visitas a fim de evitar aglomerações ${ }^{40}$.

\footnotetext{
${ }^{36}$ HEMEROTECA DIGITAL DA BIBLIOTECA NACIONAL. Folha do littoral. A Influenza Hespanhola. Camocim, 27 out. 1918, ano I, n. 20.

${ }^{37}$ RIBEIRO, 1919, p. 8.

${ }^{38}$ BARBOSA, J. P. A. Origens e desenvolvimento das políticas públicas de saúde no estado do Ceará: Ceará-1997. 1997. Tese de Doutorado. Dissertação (Mestrado)-Departamento de Saúde Comunitária/Centro de Ciências da Saúde, Universidade Federal do Ceará, p. 61.

${ }^{39}$ RIBEIRO, 1919, p. 11.

${ }^{40}$ SANTA CASA DE MISERICÓRDIA DE FORTALEZA. Acta da $13^{a}$ sessão ordinária da Mesa Administrativa da Santa Casa de Misericórdia. Fortaleza, 21 nov. 1918, p. 69.
} 
De imediato foram providenciados sete postos de saúde públicos em diferentes pontos de Fortaleza com atendimento médico gratuito ${ }^{41}$. Esses postos registraram 8.310 atendimentos por gripe espanhola no ano de $1918^{42}$. Outra estratégia adotada foi colocar as vinte e uma farmácias da cidade para atender, em regime de rodízio, no período noturno. Ainda, buscandose manter a notificação dos casos, entregou-se cadernetas para essa finalidade a todos os clínicos de Fortaleza e aos farmacêuticos, para registro dos casos de doentes que buscavam medicamentos sem prescrição médica. Entretanto, muitos não seguiram as orientações de registro $^{43}$, o que dificultou o conhecimento do real número de acometidos.

Chegando ao litoral pelos portos, o vírus propagou-se rapidamente para as cidades interioranas pelas linhas férreas. "Da capital a epidemia alastrou-se pelo interior, ao longo da Estrada de Ferro de Baturité, até o extremo sul do Estado" ${ }^{44}$, com registro de casos até a região do Araripe $^{45}$. Na época, esta linha férrea chegava até o município de Lavras da Mangabeira ${ }^{46}$, na região do Cariri, distante $390 \mathrm{~km}$ de Fortaleza. Estima-se que a doença tenha assolado todos os dezoito municípios da região caririense, chegando não somente pela linha férrea, mas também pela fronteira com Pernambuco ${ }^{47}$. Ao Oeste, a Estrada de Ferro de Sobral, saia de Camocim até o município de Crateús, distante $332 \mathrm{~km}$ da capital. Através dela, a gripe espanhola "rapidamente galopou e intensificou-se por esses sertões adentro" 48 . Houve registros do agravamento da doença nas cidades serranas da região de Ibiapaba, e no litoral leste do estado $^{49}$.

Como medidas sanitárias, o Governo do Estado designou médicos para atuarem em diversos municípios: Aracoiaba, Araripe, Barbalha, Baturité, Brejo Santo, Campos Sales, Crato, Ibiapina, Iguatu, Jardim, Lavras da Mangabeira, Milagres, Redenção, São Benedito, Senador Pompeu, Viçosa e Ubajara ${ }^{50}$. Nas pequenas localidades, que não possuíam farmácias, foram

\footnotetext{
${ }^{41}$ RIBEIRO, 1919, p. 11.; SANTA CASA DE MISERICÓRDIA DE FORTALEZA. Acta da $6^{a}$ sessão extraordinária da Mesa Administrativa da Santa Casa de Misericórdia. Fortaleza, 30 nov. 1918, p. 71.

42 HEMEROTECA DIGITAL DA BIBLIOTECA NACIONAL. Folha do Littoral. O nosso saneamento. Camocim, 25 mai. 1919 , ano 2, n. 49.

${ }^{43}$ RIBEIRO, 1919, p 20.

44 SILVA, 1919, p. 31.

${ }^{45}$ RIBEIRO, 1919, p. 26

${ }^{46}$ PEREIRA, J. H.; LIMA, F. A. S. Estradas de Ferro no Ceará. Fortaleza: Expressão Gráfica e Editora, 2009.

${ }^{47}$ PINHO, M. F. M.; ALEXANDRE, J. F. "Em toda parte só se ouvia falar em morte": A Gripe Espanhola no Cariri (1918-1919). Outros Tempos: Pesquisa em Foco-História, v. 18, n. 31, p. 249-273, 2021, p. 267.

${ }^{48}$ HEMEROTECA DIGITAL DA BIBLIOTECA NACIONAL. Diário de Pernambuco. A Influenza Espanhola. Recife, 17 out. 1918 , ano 94, n. 286.

${ }^{49}$ RIBEIRO, 1919, p. 14

${ }^{50}$ RIBEIRO, 1919, p 24-26.
} 
enviadas noventa e seis ambulâncias equipadas com medicamentos, conforme relatório do inspetor geral de higiene, Carlos Ribeiro.

Em Sobral, ao se tomar conhecimento da propagação da pandemia, a imprensa afirmou que a gripe não resistiria a temperatura de $36^{\circ}$ graus medida à sombra na cidade ${ }^{51}$. Todavia, a previsão não se cumpriu. A pandemia instalou-se na cidade. Como medidas sanitárias, adotouse a higienização dos bairros com notificações de casos da doença ${ }^{52}$ e a suspensão das aulas escolares $^{53}$.

\section{A SOCIEDADE CEARENSE E A GRIPE ESPANHOLA: IMPACTOS E ENFRENTAMENTO}

Apesar dos esforços, houve registros de óbitos até mesmo em famílias de figuras importantes para a história cearense. O poeta e educador Antônio Filgueiras Lima, natural do município Lavras da Mangabeira-CE, perdeu cinco irmãos acometidos pela gripe espanhola ${ }^{54}$. O filho do senador cearense Francisco Sá faleceu com a mesma doença ${ }^{55}$.

O dramaturgo e jornalista Carlos Torres Câmara, enquanto se recuperava da gripe, escreveu a peça teatral "A Bailarina”, que retrata a chegada da epidemia ao sertão de InhamúsCE:

Puxavante - Apois é isso, seu Manduquinha, tamo c'a desgraça na casa da farinha. É um horrô. Tem pra mim qui desta vez num escapa nem rato. E foi aquele sujeitim do Ceará que impestou tudo [...].

Peraldiana - Apois, meu irmão, aqui é morre gente todo o santo dia. É duenção! Já num se acha mais no mato, nem papaconha, nem raiz de angélca, nem mangirioba, nem cabeça-de-nêgo, o povo arrancarum tudo. Foi aquele desinfiliz qui trouxe a doença da balarina pra cá. Impestou tudo ${ }^{56}$.

\footnotetext{
${ }^{51}$ HeMEROTECA Digital DA BIBLIOTECA NACIONAL. A Lucta. Peste. Sobral, 23 out. 1918, ano V, n. 233.; HEMEROTECA DIGITAL DA BIBLIOTECA NACIONAL. A Lucta. A Peste. Sobral, 06 nov. 1918, ano V, n. 236.

${ }^{52}$ HEMEROTECA DIGITAL DA BIBLIOTECA NACIONAL. A Lucta. A Peste. Sobral, 05 de fev. 1919, ano, n. 249.

${ }^{53}$ HEMEROTECA DIGITAL DA BIBLIOTECA NACIONAL. Folha do Littoral. Telegramas. Camocim, 10 nov. 1918, ano 1, n. 22.

${ }^{54}$ LEITÃO, J. F. Ensino como quem reza: vida e tempo de Filgueiras Lima. Fortaleza: Tecnograf, 2006, p. 53.

${ }^{55}$ HEMEROTECA DIGITAL DA BIBLIOTECA NACIONAL. A Lucta. Varias. Sobral, 13 nov. 1918, ano V, n. 237.

${ }^{56}$ CÂMARA, C. A bailarina. In. CÂMARA, C. Teatro: obra completa. Fortaleza: Academia Cearense de Letras, 1979, p. 79 e 87.
} 
Câmara se notabilizou por entreter e arrancar risadas de seus expectadores, com causos bem-humorados, ricos de nuances do cotidiano. Mas também falava sério. Em "A Bailarina", o autor denunciou a autoridade dos coronéis ao obrigar que doentes pela influenza ficassem isolados, em quarentena, sem direito à assistência médica nem medicamentos para o tratamento. Também relatou a dificuldade das cidades interioranas para enfrentar a pandemia frente a um sistema de saúde precário e a falta de profissionais da área para atender a população. A carência de profissionais de saúde nesse período, apesar de ser habitual no território nacional, era ainda mais acentuada no sertão nordestino. Há relatos de que o prefeito de Sobral à época, José Jácome de Oliveira continuou exercendo a profissão de médico durante a pandemia da influenza espanhola ${ }^{57}$.

Outro problema de saúde pública recorrente era a precariedade de medicamentos e seus preços superfaturados no país por causa da guerra. Muitas vezes, a única alternativa para a população pobre era recorrer a remédios caseiros. Limão (com ou sem pinga), canela, folhas de eucalipto, cebola e alho eram alguns dos tratamentos empregados na tentativa de curar a gripe ${ }^{58}$.

Receitas de cura para o grande mal eram compartilhadas nos jornais por populares a fim de ajudar a combater a pandemia ${ }^{59}$. Por vezes, em busca de um tratamento eficaz, os próprios médicos as divulgavam. No Ceará, a fórmula prescrita pelo médico Manuelito Moreira era publicada nos jornais como capaz de erradicar a influenza espanhola: $100 \mathrm{~g}$ de infusão de sabugueiro, $100 \mathrm{~g}$ de eucalipto; $8 \mathrm{~g}$ de acetato de amônia, $3 \mathrm{~g}$ de aspirina e 10 gotas de acônito ${ }^{60}$. A indicação deste tipo de receita médica como terapêutica nos quadros da gripe releva que, ante o desconhecimento do vírus e a falta de um tratamento efetivo, a medicina recorria a remédios confeccionados com plantas medicinais que, por isso, se assemelhavam aos utilizados na medicina popular.

O poeta cearense Juvenal Galeno relatou em seu livro "Medicina caseira" através de versos os saberes acerca do uso de plantas medicinais. Ele citou dois tratamentos para a "bailarina", um deles feito a partir de chá e cozimento de alho:

\footnotetext{
${ }^{57}$ MONT'ALVERNE, J. R. História da medicina em Sobral: dos primórdios à Faculdade de Medicina. Revista do Instituto do Ceará. Ano 125,2011, p. 217.

${ }^{58}$ BERTUCCI, Liane Maria. Influenza, a medicina enferma: ciencia e praticas de cura na epoca da gripe espanhola em São Paulo. 2002. 401 p. Tese (doutorado) - Instituto de Filosofia e Ciencias Humanas, Universidade Estadual de Campinas, Campinas, SP, p. 150.

${ }_{59}$ BERTUCCI, L. M. A onipresença do medo na influenza de 1918. Varia Historia., Belo Horizonte, v. 25, n. 42, p. 457-475, 2009b, p. 470.

${ }^{60}$ HEMEROTECA DIGITAL DA BIBLIOTECA NACIONAL. Folha do Littoral. Telegramas. Camocim, 10 nov. 1918 , ano 1, n. 22.
} 
O alho, caros leitores,

Na caseira medicina,

É remédio excelente

Para gripe ou bailarina.

Usado pelos antigos,

Como chá ou cozimento,

Cura febres, cura as dores

De qualquer resfriamento ${ }^{61}$.

O outro tratamento citado por Juvenal Galeno para combater a influenza espanhola, que, segundo ele, fora indicado por um médico, era feito com o cozimento de folhas de goiabeira:

Das folhas da goiabeira

O chá não é para ceia: [...]

E como contém tanino,

Um douto da nova escola

Indicou-o, para lavagens

Durante a gripe espanhola.

$\mathrm{Na}$ boca, ventas, garganta,

Sempre às horas matinais ${ }^{62}$.

O setor empresarial de medicamentos, ante a alta demanda por tratamentos e o desespero da população em buscar um meio de prevenir-se, aproveitou para divulgar medicamentos supostamente capazes de curar o mal. Os jornais publicavam propagandas para combater os sintomas da influenza espanhola, entre elas a Emulsão Scott era anunciada como fortificante capaz de combate a gripe $^{63}$.

Em âmbito nacional o quinino configurava-se um dos tratamentos mais defendidos no combate a influenza espanhola. Composto extraído de árvores do gênero Cinchona, era utilizado desde 1820 no tratamento de malária. Na falta de conhecimento do agente causador

\footnotetext{
61 GALENO, J. Medicina caseira. Fortaleza: SECULT, 2010, p. 37.

62 GALENO, 2010, p 71 .

${ }^{63}$ HEMEROTECA DiGiTAL DA BIBLIOTECA NACIONAL. A Lucta. A Influenza Hespanhola. Sobral, 04 dez. 1918 , ano V, n. 240.; HEMEROTECA DIGITAL DA BIBLIOTECA NACIONAL. A Lucta. Collegio Diocesano. Sobral, 18 dez. 1918 , ano V, n. 242.
} 
da pandemia de influenza e de como tratá-la, a prescrição de quinino foi feita em grande escala, inclusive por Carlos Chagas ${ }^{64}$ - quando à frente da Diretoria de Saúde Pública Nacional. A indicação de medicamento sem eficácia comprovada comumente figura como uma estratégia política e econômica de transmitir a população a falsa sensação de que existe cura para o mal que a assola, tal qual se vivencia atualmente com a pressão pelo governo brasileiro e de outros países para a inclusão de cloroquina e hicroxicloroquina no protocolo terapêutico de Covid-19, quando não há nenhuma evidência científica da eficácia desses compostos para essa finalidade.

Endossando esse discurso, no Ceará, figuraram adeptos do quinino que propagavam nos jornais a importância deste para a cura da gripe pandêmica e, com isso, defendiam não haver motivo para preocupação ${ }^{65}$. Contudo, a eficiência da substância acabou caindo em descrédito entre os médicos locais, conforme noticiou a imprensa ${ }^{66}$. Do mesmo modo, no Rio de Janeiro, o uso do quinino dividiu opiniões entre membros da elite a respeito de sua efetividade no combate à "espanhola":

- Não há como quinino! - afirmava um.

- Qual quinino, qual nada! - gritava outro.

- E ahi estão os milhares de indivíduos que morreram com essa medicação.

- Eu tomei quinino e não morri! ${ }^{67}$.

Em contrapartida, os cientistas buscaram produzir vacina capaz de prevenir a doença a partir da filtração de escarros e da extração de sangue em pessoas sintomáticas ${ }^{68}$. A imprensa cearense noticiou que Vital Brasil, médico mineiro diretor do Instituto Butantan, havia descoberto "uma vacina contra a influenza que é preparada com germens extraídos de pessoas enfermas. A nova vacina tem feito sucesso" ${ }^{\text {"9 }}$. Mesmo com o entusiasmo da imprensa e os esforços da ciência, nenhuma vacina foi fabricada a tempo.

\footnotetext{
${ }^{64}$ HEMEROTECA DIGITAL DA BIBLIOTECA NACIONAL. Folha do Litoral. Gonstas \& Fatos. Camocim, 03 nov. 1918, ano I, n. 21.

${ }^{65}$ HEMEROTECA DIGITAL DA BIBLIOTECA NACIONAL. Folha do Litoral. A influenza Hespanhola. Camocim, 27 out. 1918, ano I, n. 20.

${ }^{66}$ HEMEROTECA DIGITAL DA BIBLIOTECA NACIONAL. Folha do Litoral. Gonstas \& Fatos. Camocim, 03 nov. 1918, ano I, n. 21.

${ }^{67}$ HEMEROTECA DIGITAL DA BIBLIOTECA NACIONAL. A Lucta. Tintura-Mãe. Sobral, 25 jun. 1921, ano VIII, n. 440.

${ }^{68}$ GOULART, 2005, p. 131.

${ }^{69}$ HEMEROTECA DIGITAL DA BIBLIOTECA NACIONAL. Folha do Litoral. Gonstas \& Fatos. Camocim, 03 nov. 1918, ano I, n. 21
} 
Tão impressionante quanto os efeitos da doença foi o descaso das autoridades com a população pobre. A Diretoria Geral de Higiene do Ceará relatou que a quase totalidade de óbitos ocorreu entre as camadas sociais empobrecidas e que, dentre elas, pouquíssimas pessoas não adoeceram ${ }^{70}$. Consta em relatório enviado pelo presidente da Província do Ceará à Assembleia legislativa, João Thomé de Saboya e Silva, que a moléstia teria causado prejuízos, praticamente, apenas aos grupos desfavorecidos da sociedade:

Entre a população que dispõe de qualquer recurso e de alguma instrução, a moléstia foi benigníssima; quase todas as vítimas (excetuados alguns indivíduos já lesados organicamente) se registram nas classes mais pobres que habitam palhoças e não podem ou não querem se submeter às prescrições médicas. ${ }^{71}$.

O fato de a gripe espanhola ter feito a maioria de suas vítimas entre as camadas sociais mais pobres no Ceará expõe a desigualdade ante uma pandemia. Com o aumento dos preços de alimentos e medicamentos por causa da guerra, as pessoas mais pobres encontravam-se em agravante fragilização ocasionada pela má alimentação, pelo reduzido poder aquisitivo para a busca de tratamentos e pela falta de acesso à informação, visto que, as notícias e as instruções de cuidados higiênicos eram veiculadas majoritariamente nos jornais impressos. Ao mesmo tempo, muitas famílias não tinham condições de evitar aglomerações - dada a precariedade de suas residências - ou da natureza de suas ocupações.

Schwarcz e Starling ${ }^{72}$ atentaram para o fato de as mortes não afetarem a sociedade de forma indiscriminada. Pelo contrário, escancaram as desigualdades sociais que estruturam o Brasil. Cor, classe social, escolaridade e local de moradia se tornam fatores centrais para a população que sofre com a difusão da doença e suas consequências mais graves.

Após o carnaval de 1919 notou-se o aumento dos casos na cidade de Fortaleza, havendo registros de doentes pelo menos até maio do mesmo ano. Até esse mês, o número de casos atendidos reportados às autoridades sanitárias desde o início da pandemia foi somente 15.959, com mais de $99 \%$ registrado somente em outubro e novembro de 1918. Este número se deve

\footnotetext{
${ }^{70}$ RIBEIRO, 1919, p. 13 e 15.

${ }^{71}$ SILVA, 1919, p. 31.

72 SCHWARCZ; STARLING, 2020, p. 172.
} 
não ao arrefecimento da pandemia, mas ao não funcionamento do sistema de notificação, quase que cessando totalmente os registros a partir de dezembro do mesmo ano ${ }^{73}$, além dos casos em que os doentes não buscaram atendimento médico. O que levou a Diretoria Geral de Higiene à estimativa de 35.000 casos. Em Fortaleza, apontou-se 343 óbitos entre outubro de 1918 e abril de 1919. No Cariri, registrou-se 1.078 mortes e, embora a imprensa cearense tenha divulgado que os casos cessaram no início de 1919, houve registos de sepultamento pela doença durante praticamente todo esse ano na região do Cariri, e até outubro no município serrano de Maranguape ${ }^{74}$. Quanto ao número de mortos, não há registro oficial da quantidade total de vitimados pela gripe espanhola no território cearense.

\section{CONCLUSÃO}

Em momentos turbulentos (como o de enfrentamento de grande flagelo), a ansiedade e o desejo de superar as agruras do presente nos impõem a necessidade revisitar o passado. Cabe aos cientistas, das mais distintas áreas, rever casos e situações diversas no decurso do tempo, que guardem alguma similitude com os apuros sofridos pela sociedade na atualidade. Munidos dessa inquietação, surgiu o interesse de refletir sobre um evento pandêmico. A gripe espanhola foi escolhida por ser um evento de maior similaridade - em termos de contágio, prevenção e proporções - ao da COVID-19 e, por não haver nenhum estudo, até o ano de 2020, que lançasse um olhar aprofundado sobre esse tema no Ceará.

Naquele momento, ainda sofrendo com os conflitos da Primeira Guerra Mundial, o mundo teve de enfrentar um inimigo invisível, que não escolhia lado da trincheira para atacar. No Brasil, testemunhou-se a morte de milhares de pessoas em face do rápido avanço da moléstia. Antes, como agora, uma grave enfermidade respiratória representou o espectro de uma ameaça iminente de morte em larga escala.

A consulta a periódicos cearenses correntes no período foi essencial para a compreensão dos impactos causados pela doença, da repercussão em torno dos discursos veiculados em matérias e editoriais jornalísticos. A análise das estratégias empreendidas pelas autoridades locais foi compilada através da leitura de documentos oficiais.

\footnotetext{
${ }^{73}$ RIBEIRO, 1919, p. 20.

${ }^{74}$ PINHO; ALEXANDRE, 2021, p. 270 e 271.
} 
O trabalho teve o intuito de analisar os impactos sociais causados e as medidas adotadas no combate à pandemia de gripe espanhola no estado do Ceará. Através da pesquisa foi possível identificar como o vírus chegou, e de que forma ele se difundiu em processo de interiorização: o Vapor Ceará foi um dos primeiros navios a desembarcar pessoas infectadas, em Fortaleza ainda em setembro de 1918; indivíduos doentes se deslocaram para o interior do Ceará, sobretudo, a partir das estradas de ferro de Baturité e de Sobral, assim como através de estradas de terra interior adentro.

Fortaleza e os demais municípios cearenses enfrentaram a "bailarina", contabilizando mortes, principalmente entre os grupos mais pobres da sociedade. O Estado e a população reagiram à pandemia: ora negando seus efeitos - o que, obviamente, serviu de campo fértil ao florescimento da doença no seio da sociedade cearense; ora atuando de maneira direta no combate à doença, ainda que desprovida de recursos eficazes.

Ante a carência de medicamentos efetivos contra a moléstia, sobretudo, em virtude da falta de conhecimentos científicos mais consistentes acerca dos agentes causadores, meios caseiros de tratamento à base de produtos naturais (limão, canela, cebola, alho, folhas de eucalipto, etc.) foram utilizados de forma ampla. Produtos industrializados como emulsões, tônicos e até pinga foram comercializados, contudo sem efeito significativo.

Naquele momento, a inexistência de um serviço de saúde público unificado também foi um dos maiores obstáculos no enfrentamento a pandemia. $\mathrm{O}$ mesmo fato também afetou na construção desse estudo, seja pela falta de padronização dos dados encontrados, seja pela escassez de dados referentes aos impactos provocados pela moléstia em outros municípios, o que, em certa medida, acaba por impedir, a princípio, maior aprofundamento da análise.

O crescente interesse em estudar a gripe espanhola no Brasil é relativamente recente. Nestes termos, o estado do Ceará carece de maior volume de estudos que abordem o tema. Decerto há amplo campo de pesquisa ainda pouco explorado até o momento. Entendemos a contribuição desse trabalho em termos exploratórios para distintos aspectos. Sabemos que é preciso verticalizar a análise em outras regiões do estado para ter maior apreensão acerca da temática enfocada. 


\section{REFERÊNCIAS}

\section{Fontes}

CÂMARA, C. A bailarina. In. CÂMARA, C. Teatro: obra completa. Fortaleza: Academia Cearense de Letras, 1979.

CEARÁ. Decreto Legislativo N. ${ }^{\circ} 1643$, de 8 de novembro de 1918. Regulamento Da Directoria Geral de Hygiene. Fortaleza: Est. Graphico A. C. Mendes, 1919.

GALENO, J. Medicina caseira. Fortaleza: SECULT, 2010.

HEMEROTECA DIGITAL DA BIBLIOTECA NACIONAL. A Lucta. Tintura-Mãe. Sobral, 25 jun. 1921, ano VIII, n. 440. Folha do Littoral. Edições indicadas, 1918 e 1919.

_. A Lucta. Edições indicadas. 1918 e 1919.

_. Communicado da Directoria Geral de Hygiene. Sobral, 23 out. 1918, ano V, n. 233.

. Diário de Pernambuco. Edições indicadas, 1918 e 1919.

RIBEIRO, C. C. Relato da Diretoria Geral de Saúde: 31 de maio de 1919. Fortaleza: Tipografia Moderna, 1919.

SANTA CASA DE MISERICÓRDIA DE FORTALEZA. Acta da $13^{a}$ sessão ordinária da Mesa Administrativa da Santa Casa de Misericórdia. Fortaleza, 21 nov. 1918.

. Acta da $6^{a}$ sessão extraordinária da Mesa Administrativa da Santa Casa de Misericórdia. Fortaleza, 30 nov. 1918.

SILVA, J. T. S. Mensagem apresentada pelo presidente do estado à Assembleia Legislativa do Ceará. Fortaleza, 01 jul. 1919.

STUDART, G. Ephemerides Cearenses. Revista Trimensal do Instituto do Ceará. Ano 32, p.252-258, 1918.

\section{Obras Gerais}

ALMEIDA, M. A. P. A epidemia de cólera de 1853-1856 na imprensa portuguesa. História, Ciências, Saúde - Manguinhos, Rio de Janeiro, v.18, n.4, p.1057-1071, 2011. Disponível em: <https://doi.org/10.1590/S0104-59702011000400006>. Acesso em: 19 mai. 2020 
BARBOSA, J. P. A. Origens e desenvolvimento das políticas públicas de saúde no estado do Ceará: Ceará-1997. 1997. 223p. Dissertação (Mestrado) - Departamento de Saúde Comunitária/Centro de Ciências da Saúde, Universidade Federal do Ceará, Fortaleza, CE.

BERTUCCI, L. M. Gripe A, uma nova "espanhola"? Revista da Associação Médica Brasileira, São Paulo, v. 55, n. 3, p. 230-231, 2009a. Disponível em: $<$ http://www.scielo.br/scielo.php?script=sci_arttext\&pid=S0104-

42302009000300001\&lng=en\&nrm=iso>. Acesso em: 13 mai. 2020.

. A onipresença do medo na influenza de 1918. Varia Historia., Belo Horizonte, v. 25, n. 42, p. 457-475, 2009b. Disponível em: <http://www.scielo.br/scielo.php?script=sci_arttext\&pid=S0104-

87752009000200005\&lng=en\&nrm=iso>. Acesso em: 18 mai. 2020.

. Influenza, a medicina enferma: ciência e práticas de cura na época da gripe espanhola em São Paulo. 2002. 401 p. Tese (Doutorado) - Instituto de Filosofia e Ciências Humanas, Universidade Estadual de Campinas, Campinas, SP.

COSTA, M. C. L. Capítulos de geografia histórica de Fortaleza. Fortaleza: Imprensa Universitária, 2017.

CUETO, M. El regreso de las epidemias: salud y sociedad en el Perú del siglo XX. Lima: Instituto de Estudios Peruanos, 2020.

GOULART, A. C. Revisitando a espanhola: a gripe pandêmica de 1918 no Rio de Janeiro. História, ciências, saúde-Manguinhos, v. 12, n. 1, p. 101-142, 2005.

JOHNSON, N. P.; MUELLER, J. Updating the accounts: global mortality of the 1918-1920" Spanish" influenza pandemic. Bulletin of the History of Medicine, v. 76, n. 1, p. 105-115, 2002.

KHODR, O. B. O Pesadelo Econômico Moderno: a pandemia e a possível depressão da nova década. Boletim Economia Empírica, v. 1, n. 2, p. 3-7, 2020. Disponível em: <https://www.portaldeperiodicos.idp.edu.br/bee/article/download/4123/1798>. Acesso em: mai. 2020.

LEITÃO, J. F. Ensino como quem reza: vida e tempo de Filgueiras Lima. Fortaleza: Tecnograf, 2006.

MONT'ALVERNE, J. R. História da medicina em Sobral: dos primórdios à Faculdade de Medicina. Revista do Instituto do Ceará. Ano 125, p.209-233, 2011. Disponível em: https://www.institutodoceara.org.br/revista/Rev-

apresentacao/RevPorAno/2011/RevdoInstituto_2011_PDFcompleto.pdf Acesso em: 15 mai. 2020.

PEIRIS, J. S M.; POON, L. L. M.; GUAN, Y. Emergence of a novel swine-origin influenza A virus (S-OIV) H1N1 virus in humans. Journal of Clinical Virology, v. 45, n. 3, p. 169-173, 2009. 
PEREIRA, J. H.; LIMA, F. A. S. Estradas de Ferro no Ceará. Fortaleza: Expressão Gráfica e Editora, 2009.

PINHO, M. F. M.; ALEXANDRE, J. F. "Em toda parte só se ouvia falar em morte": A Gripe Espanhola no Cariri (1918-1919). Outros Tempos: Pesquisa em Foco-História, v. 18, n. 31, p. 249-273, 2021.

POTTER, C. W. A history of influenza. Journal of applied microbiology, v. 91, n. 4, p. 572579 , 2001. Disponível em: https://sfamjournals.onlinelibrary.wiley.com/doi/full/10.1046/j.1365-2672.2001.01492.x Acesso em: 11 mai. 2020.

ROSENBERG, C. E. Explaining epidemics and Other Studies in the History of Medicine. Cambridge: Cambridge University Press, 1992.

ROTHER, E. T. Revisão sistemática X revisão narrativa. Acta paulista de enfermagem, v. 20, n. 2, p. 5-6, 2007. Disponível em: https://www.scielo.br/scielo.php?pid=S010321002007000200001\&script=sci_arttext\&tlng=pt Acesso em: 11 mar. 2020.

SANTOS, R. A. O Carnaval, a peste e a 'espanhola'. História, Ciências, Saúde-Manguinhos, v. 13, n. 1, p. 129-158, 2006.

SAUNDERS-HASTINGS, P. R.; KREWSKI, D. Reviewing the history of pandemic influenza: understanding patterns of emergence and transmission. Pathogens, v. 5, n. 66, p. 1-19, 2016. Disponível em: https://www.mdpi.com/2076-0817/5/4/66/htm\#B29-pathogens-05-00066 Acesso em: 13 mai. 2020.

SCHWARCZ, L. M.; STARLING, H. M. A bailarina da morte: a gripe espanhola no Brasil. São Paulo: Companhia das Letras, versão (digital), 2020.

SILVEIRA, A. J. T. A medicina e a influenza espanhola de 1918. Tempo, v. 10, n. 19, p. 91105, 2005. Disponível em: https://www.scielo.br/scielo.php?pid=S141377042005000200007\&script=sci_arttext\&tlng=pt Acesso em: 10 de mai. 2020.

SILVA, C. E. M. A missão médica especial brasileira de caráter militar na Primeira guerra mundial. Revista Navigator, v. 10, n. 20, p. 94-108, 2011. Disponível em: https://www.revistanavigator.com.br/navig20/art/N20_art2.pdf Acesso em: 16 mai. 2020.

SOUZA, C. M. C. A gripe espanhola em Salvador, 1918: cidade de becos e cortiços. História, ciências, saúde-Manguinhos, v. 12, n. 1, p. 71-99, 2005. Disponível em: https://www.scielo.br/scielo.php?pid=S0104-59702005000100005\&script=sci arttext Acesso em: 16 dez. 2020.

A gripe espanhola na Bahia: saúde, política e medicina em tempos de epidemia. Editora Fiocruz, 2009. 
STEVENS, K. M. The pathophysiology of influenzal pneumonia in 1918. Perspectives in biology and medicine, v. 25, n. 1, p. 115-125, 1981. Disponível em: https://muse.jhu.edu/article/404498/pdf Acesso em: 05 mai. 2020.

TRILlA, A.; TRILlA, G.; DAER, C. The 1918 "Spanish flu" in Spain. Clinical infectious diseases, v. 47, n. 5, p. 668-673, 2008.

TUCIDIDES. A história da guerra do Poliponeso. Brasília: Editora UnB; 2001.

WALDMAN, E. A.; SATO, A. P. S.; FORTALEZA, C. M. C. B. Doenças infecciosas no Brasil: das endemias rurais às modernas pandemias. In: MONTEIRO, C. A.; LEVY, R.B. (org.s). Velhos e novos males da saúde no Brasil: de Geisel a Dilma. São Paulo: Hucitec, v. 1, 2015, p. 234-311. 